01

\title{
Исследование объемного радиационного переноса тепла в кристалле и расплаве с помощью численного моделирования при выращивании кристаллов сапфира методом Степанова
}

\author{
(C) М.Г. Васильев, С.И. Бахолдин, В.М. Крымов
}

Физико-технический институт им. А.Ф. Иофрфе РАН, 194021 Санкт-Петербург, Россия

e-mail: vasiliev.mg@yandex.ru

Поступило в Редакцию 4 декабря 2019 г.

В окончательной редакции 11 февраля 2020 г.

Принято к публикации 17 февраля 2020 г.

\begin{abstract}
Методом численного моделирования изучен эффект объемного радиационного переноса тепла при выращивании профилированных кристаллов сапфира из расплава. Рассмотрены особенности структуры световодного потока в кристалле и расплаве, а также возможность появления радиационной неустойчивости границы раздела фаз. Показано наличие переохлажденных областей под фронтом кристаллизации, размер которых зависит от скорости выращивания. Установлено, что использование конструкции конического формообразователя привело к более устойчивому процессу выращивания.
\end{abstract}

Ключевые слова: сапфир, метод Степанова (EFG), радиационное переохлаждение расплава.

DOI: $10.21883 /$ JTF.2020.08.49531.385-19

\section{Введение}

В последние годы появилось много работ по численному моделированию процессов роста монокристаллов сапфира, выращиваемых из расплава различными методами. Это связано с широким применением сапфира в современной технике в качестве оптических окон и подложек светодиодов. Современные мощные программные вычислительные пакеты позволяют моделировать процессы роста и тем самым совершенствовать технологии, улучшать качество кристаллов и повышать производительность процесса. Например, для процесса выращивания сапфира методом Степанова (EFG - Edgedefined film-fed growth) в [1] с помощью вычислительного пакета COMSOL Multiphysics software проведено численное моделирование формы фронта кристаллизации при выращивании стержней и лент, что позволило оптимизировать тепловую зону для выращивания качественных пластин большого размера. Радиационный перенос тепла учитывался путем введения радиационных источников в уравнение теплопереноса. Фактически использовалось Р1-приближение [2], которое, как и приближение лучистой теплопроводности Росселанда, дает приемлемые результаты для случая оптически толстых сред. Коэффициент поглощения считался равным $20 \mathrm{~m}^{-1}$, а внешняя поверхность кристалла - диффузно отражающей. Авторы пренебрегали потоком излучения на границе раздела кристалл-расплав, считая, что он слабо влияет на распределение температуры и форму фронта кристаллизации. В [3] по той же модели рассчитывалась форма фронта кристаллизации при выращивании сапфира методом Киропулоса. В [4] моделировался рост сапфира методами Киропулоса и Чохральского, и учет радиационного переноса был выполнен с помощью комбинации методов трассировки лучей и дискретных ординат [5]. Этот метод позволяет учитывать взаимодействие излучения со средой, корректно описывать диффузные и зеркальные отражения и преломление лучей на границах. За последние годы в разных вариантах моделировались также тепловые зоны для выращивания кристаллов сапфира другими методами [6-8]. В этих работах изучалось влияние различных технологических факторов на процесс выращивания сапфира.

В большинстве работ расплав считался сильно поглощающим, и для учета радиационного переноса использовалось приближение Росселанда, суть которого сводится к введению добавки эффективного коэффициента радиационной теплопроводности к обычной кондуктивной составляющей. При этом считается, что отвод тепла от расплава посредством излучения происходит непосредственно с фронта кристаллизации. Однако этот подход не позволяет учесть эффект переохлаждения расплава, вызванный переносом тепла излучением из объема расплава в кристалл через границу раздела фаз.

Корректный учет этих факторов существенно влияет на форму фронта кристаллизации, а в некоторых случаях может приводить и к его неустойчивости. Это явление впервые было предсказано в $[9,10]$.

Поэтому целью настоящей работы было численное исследование влияния объемного радиационного переноса тепла в твердой и жидкой фазах на процессы теплообмена при выращивании кристаллов сапфира из расплава методом Степанова. Для моделирования радиационного переноса использовалась комбинация двух методов: трассировки лучей и дискретных ординат. 


\section{1. Особенности переноса тепла в полупрозрачных тугоплавких кристаллах и расплавах для метода Степанова}

В полупрозрачных тугоплавких кристаллах перенос тепла осуществляется в основном за счет теплового излучения, что может быть оценено с помощью кондуктивно-радиационного параметра $N$

$$
N=k \lambda /\left(4 n^{2} \sigma T^{3}\right) .
$$

Здесь $k, \lambda-$ коэффициенты поглощения теплового излучения и теплопроводности, $n-$ коэффициент преломления, $\sigma$ - постоянная Стефана-Больцмана и $T$ - температура в К. Для сапфира при температуpax, близких к температуре плавления, $N=0.01$. Это означает превышение радиационного потока тепла в 100 раз по сравнению с кондуктивной компонентой. Коэффициент поглощения теплового излучения расплавом сапфира равен примерно $1400 \mathrm{~m}^{-1}$ [11], что почти на 2 порядка выше соответствующего коэффициента для кристалла $-k_{\text {cryst }}=17 \mathrm{~m}^{-1}[12,13]$. В результате в расплаве параметр $N$ порядка единицы. Однако изза малой толщины мениска $h$ расплава (в пределах от 0.1 до $0.5 \mathrm{~mm}$ ) отношение кондуктивного потока к радиационному определяется уже выражением $N / \tau^{2}$, где $\tau=k_{\text {melt }} h-$ оптическая толщина слоя мениска колеблется от 0.14 до 0.7. Таким образом, ситуация с соотношением кондуктивного и радиационного потока меняется от доминирования кондуктивной компоненты до примерного равного вклада обоих потоков. Здесь следует отметить две особенности: во-первых, слой мениска расплава может быть достаточно прозрачен для теплового излучения, и, во-вторых, в слое расплава может образоваться переохлажденная область, где температура ниже температуры кристаллизации. Последнее может быть объяснено тем, что температура на фронте кристаллизации поддерживается за счет выделения скрытой теплоты плавления, а унос энергии осуществляется тепловым излучением не только из кристалла, но и из расплава, что впервые было отмечено в [9].

Унос тепла излучением из области вблизи фронта кристаллизации в более холодную часть кристалла становится еще более сильным в случае гладкой боковой поверхности кристалла вследствие зеркального (френелевского) отражения лучей. Впервые это явление было замечено в работе [14], где использовалась модель световодного приближения радиационно-кондуктивного теплообмена для тонких профилированных кристаллов. Следует отметить, что в реальных условиях роста боковая поверхность кристалла такова, что отражение от нее более близко к зеркальному случаю, чем к диффузному.

Из-за малого кондуктивно-радиационного параметра $N$ возникает температурный пограничный слой [15], в котором вклад теплопроводности в перенос тепла существенно возрастает, что обеспечивает непрерывность функции температуры вблизи межфазной границы. Поскольку температура в пограничном слое убывает экспоненциально, для уменьшения термоупругих напряжений в кристалле требуется компенсировать потери тепла излучением из области вблизи фронта кристаллизации подводом тепла извне за счет тепловых экранов. Для тонких ленточных кристаллов такой подход дал возможность выращивать их с хорошим качеством и с достаточно высокими скоростями [16].

Для толстых кристаллов ситуация становится более сложной. Особенно заметно это проявляется для цилиндрических кристаллов в форме круглых трубок и стержней. Здесь неоднородность создает геометрия лучей, выходящих наружу из объема кристалла без полного внутреннего отражения. Именно эти лучи ответственны за радиационный обмен энергией с окружающей средой и в дальнейшем называются несветоводными. Оставшаяся часть лучей называется световодными.

Рассмотрим эту дополнительную неоднородность для простоты на примере кристалла в виде прямого кругового цилиндра. Если направить ось $Z$ по оси цилиндра, а углы $\Theta$ и $\varphi$ выбрать как в случае сферической системы координат, но с началом координат в рассматриваемой точке сечения $(x, y, z)=(r, 0, z)$, то область углов, из которой лучи выходят наружу (без полного внутреннего отражения), будет иметь вид

$$
\begin{aligned}
\Omega= & \left(r / R, \Theta_{B}\right)= \\
= & \left\{\begin{array}{l}
\left\{\Phi\left(r / R, \Theta_{B}\right) \leq \varphi \leq \Phi\left(r / R, \Theta_{B}\right)\right\} \\
\cup\left\{2 \pi-\Phi\left(r / R, \Theta_{B}\right) \leq \varphi \leq 2 \pi+\Phi\left(r / R, \Theta_{B}\right)\right\} \\
:\left\{\alpha\left(r / R, \Theta_{B}, \varphi\right)<\Theta<\pi-\alpha\left(r / R, \Theta_{B}, \varphi\right)\right\}
\end{array}\right\}
\end{aligned}
$$

где $R-$ внешний радиус цилиндра, $\Theta_{B}=\arcsin (1 / n)-$ угол полного внутреннего отражения для кристалла с коэффициентом преломления $n$, а функции $\Phi\left(r / R, \Theta_{B}\right)$ и $\alpha\left(r / R, \Theta_{B}, \varphi\right)$ равны

$$
\begin{gathered}
\Phi\left(r / R, \Theta_{B}\right)=\arcsin \left[\min \left(1, \frac{\sin \Theta_{B}}{r / R}\right)\right], \\
\alpha\left(r / R, \Theta_{B}, \varphi\right)=\arcsin \left(\frac{\cos \Theta_{B}}{\sqrt{1-(r / R)^{2} \sin ^{2} \varphi}}\right) .
\end{gathered}
$$

На оси симметрии кристалла $\Omega$ будет выглядеть так:

$$
\Omega\left(0, \Theta_{B}\right)=\left\{\pi / 2-\Theta_{B}<\Theta<\pi / 2+\Theta_{B}, 0 \leq \varphi<2 \pi\right\},
$$

а для области, близкой к боковой поверхности $\Omega$, составит:

$$
\begin{aligned}
& \Omega\left(1, \Theta_{B}\right)= \\
& =\left\{\left\{0<\Theta^{\prime}<\Theta_{B}\right\} \cup\left\{\pi-\Theta_{B}<\Theta^{\prime}<\pi\right\}, 0 \leq \varphi^{\prime}<2 \pi\right\} .
\end{aligned}
$$

Формула для величины телесного угла, занимаемого несветоводными лучами, $\Omega$ в любой точке сечения будет 


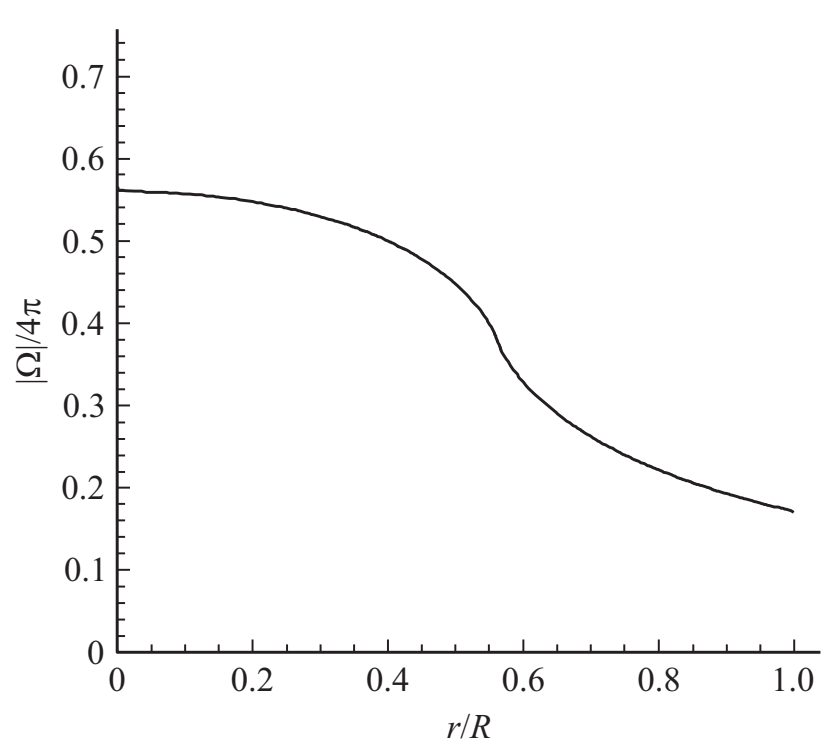

Рис. 1. Распределение доли полного телесного угла, приходящейся на область несветоводных лучей, по поперечному сечению прямого кругового цилиндра.

иметь вид

$$
\left|\Omega\left(r / R, \Theta_{B}\right)\right|=\int_{0}^{\Phi\left(r / R, \Theta_{B}\right)} d \varphi \sqrt{\frac{\sin ^{2} \Theta_{B}-(r / R)^{2} \sin ^{2} \varphi}{1-(r / R)^{2} \sin ^{2} \varphi}} .
$$

Отношение значений телесных углов областей $\Omega\left(1, \Theta_{B}\right)$ к $\Omega\left(0, \Theta_{B}\right)$ будет равно

$$
\begin{aligned}
& \left|\Omega\left(1, \Theta_{B}\right)\right| /\left|\Omega\left(0, \Theta_{B}\right)\right| \\
& =\left[1-\cos \Theta_{B}\right] / \sin \Theta_{B}=n\left(1-\sqrt{1-n^{-2}}\right) .
\end{aligned}
$$

Для сапфира $n=1.78$, и это отношение равно примерно 0.3 , т.е. величина телесного угла области лучей, выходящих наружу из средней части кристалла, более чем в 3 раза превышает соответствующую величину для областей, близких к боковой поверхности. Распределение по радиусу значений телесного угла, занимаемого несветоводными лучами (выходящими наружу без полного внутреннего отражения и замещающимися внешним излучением), по отношению к величине полного телесного угла, представлено на рис. 1. Это означает, что световодный поток в направлении выращивания неоднороден по сечению и формируется главным образом за счет лучей, распространяющихся вблизи боковой поверхности.

Представленные выше оценки справедливы только для оптически тонких в радиальном направлении кристаллов. В частности, для сапфира радиус кристалла $\mathrm{R}$ должен быть много меньше $R \ll 1 / k_{\text {cryst }}=5.9 \mathrm{~cm}$, т.е. порядка $1 \mathrm{~cm}$ и меньше. Для более толстых кристаллов имеет место большее поглощение в объеме кристалла излучения, выходящего из внутренних областей, в результате чего неоднородность в распределении радиационных потерь будет сглаживаться. Отметим, что и в совсем тонких кристаллах эффект неоднородности световодного потока по сечению тоже существует, но мало сказывается на конечном распределении температуры по сечению из-за выравнивающего влияния молекулярной теплопроводности, что и обеспечило применимость в этом случае более простых моделей радиационнокондуктивного теплообмена [14]. Для средних значений радиуса кристалла указанная неоднородность светового потока может приводить к локальным искривлениям изотерм температур, фронта кристаллизации и появлению в расплаве переохлажденных областей.

Известно, что при выращивании цилиндрических кристаллов сапфира наблюдается появление в процессе роста в средней части кристалла полостей, заполненных переохлажденным расплавом, которые после охлаждения приводят к появлению усадочных полостей и дополнительным термоупругим напряжениям. Вполне вероятно, что причиной указанного явления служит описанное выше обстоятельство.

Следует выделить еще один безразмерный параметр $B$ :

$$
B=\frac{\gamma \rho_{\text {cryst }} V_{g}}{\lambda_{\text {cryst }} G_{\text {cryst }}}
$$

где $\gamma-$ скрытая теплота плавления; $\rho_{\text {cryst }}, \lambda_{\text {cryst }}-$ удельная плотность и коэффициент теплопроводности кристалла при температуре плавления; $V_{g}-$ скорость кристаллизации; $G_{\text {cryst }}$ - градиент температуры в кристалле на фронте со знаком минус. Как показано в $[9,10]$, при параметре $B>1$ в объеме расплава появляется переохлажденная примыкающая к фронту кристаллизации область, а при $B>2$ может происходить потеря устойчивости фронта. Кратко это объясняется следующим образом: тепло, выделяемое при кристаллизации расплава, отводится в случае $B>1$ и в расплав и в кристалл, но при $B>2$ положение фронта становится неустойчивым из-за примерного равенства кондуктивных потоков в обе стороны от фронта кристаллизации. В [10] это явление было названо радиационной (по аналогии с концентрационной) неустойчивостью границы раздела фаз.

\section{2. Анализ и выбор исходных данных для модельных расчетов}

Адекватность результатов расчетов определяется не только правильной и полной моделью процессов радиационно-кондуктивного теплообмена в тепловой зоне, но и точным выбором численных значений физических свойств материалов зоны с учетом температурной зависимости. Наибольшие проблемы возникают с выбором величин коэффициентов поглощения теплового излучения в кристалле и расплаве. Это связано с тем, что указанный коэффициент сильно зависит не только от температуры и длины волны теплового излучения, но и от наличия примесей и дефектов в кристалле. 


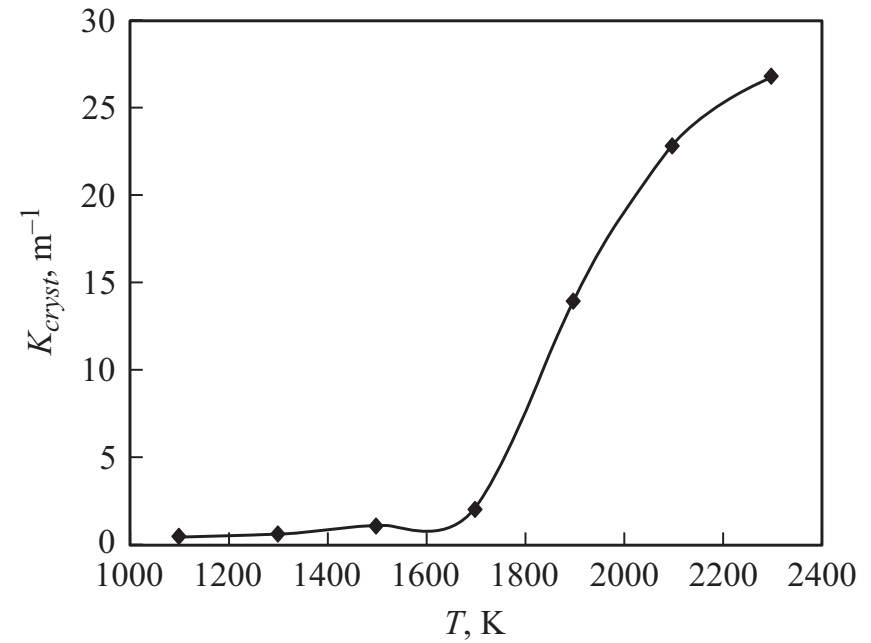

Рис. 2. Зависимость коэффициента поглощения кристалла сапфира от температуры.

\section{1. Коэффициент поглощения в кристаллах сапфира}

Наиболее полно температурные и частотные зависимости оптических свойств кристаллов сапфира были изучены в [12,13]. В [12] приведены данные по коэффициенту поглощения в сапфире $k_{c r y s t}$ в диапазоне длин волн от 0.5 до $7 \mu \mathrm{m}$ и температур от 300 до $2300 \mathrm{~K}$. По этим данным была построена зависимость $k_{\text {cryst }}(T)$, показанная на рис. 2, где каждой температуре соответствует $k_{\text {cryst }}$ на длине волны, соответствующей максимуму излучения абсолютно черного тела. Из графика видно, что в диапазоне температур от точки плавления до $1700 \mathrm{~K}$ коэффициент поглощения падает примерно на порядок.

К сожалению, используемая нами расчетная программа не предусматривала учет зависимости $k_{\text {cryst }}$ от температуры. Поэтому при расчетах было использовано значение $k_{\text {cryst }}=17 \mathrm{~m}^{-1}$, как базовое. Для оценки влияния величины коэффициента поглощения в кристалле были также проведены расчеты при значениях $k_{\text {cryst }}=5$ и $40 \mathrm{~m}^{-1}$.

\section{2. Коэффициент поглощения в расплаве сапфира}

Экспериментальных данных по спектральной и температурной зависимостям коэффициента поглощения в расплаве $k_{\text {melt }}$ сапфира в литературе много, однако все они имеют большой разброс. В работе [17] собраны данные по $k_{\text {melt }}$, полученные из экспериментов на полидисперсных частицах оксида алюминия, расплавленных в водородно-кислородных горелках. Приводятся данные от 1340 до $158000 \mathrm{~m}^{-1}$.

В [18] приведены данные измерений Лингарта (рис. 2.45) коэффициентов поглощения кристалла и расплава вблизи границы фазового перехода. Из этих данных следует, что коэффициент поглощения зависит от длины волны теплового излучения, возрастает с повышением температуры и скачком увеличивается на границе перехода. Численно можно определить коэффициент поглощения в диапазоне длин волн от 0.6 до $3 \mu \mathrm{m}$, составляющий в кристалле $16-30 \mathrm{~m}^{-1}$ и в расплаве $100-120 \mathrm{~m}^{-1}$.

Наиболее надежные данные получены недавно в работе [11], где предложен новый метод измерения коэффициента поглощения в расплаве, и получено значение $k_{\text {melt }}=(1400 \pm 200) \mathrm{m}^{-1}$ в спектральном диапазоне полупрозрачности сапфира $1-1.4 \mu \mathrm{m}$ вблизи точки плавления. Измерения были выполнены при выращивании тонких нитей сапфира с пьедестала (LHPG - Laser heat pedestal growth), что наиболее близко к нашему процессу роста.

Таким образом, на основании анализа вышеприведенных данных для расчетов основной модели были выбраны значения $k_{\text {cryst }}=17 \mathrm{~m}^{-1}$ и $k_{\text {melt }}=1400 \mathrm{~m}^{-1}$.

Значение коэффициента черноты границы расплав-формообразователь берется равным 0.4, так как при расчетах предполагалось, что формообразователь выполнен из молибдена. Коэффициент черноты молибдена для зеркальной поверхности при температуре плавления сапфира в газовой атмосфере составляет величину 0.25 [19]. По оценкам радиационных свойств материалов с помощью электромагнитной теории для границы с оптически более плотной средой (расплав-сапфир), а также для шероховатой поверхности коэффициент черноты должен быть больше. Выбранное в настоящей работе значение 0.4 соответствует минимальной возможной границе этой величины.

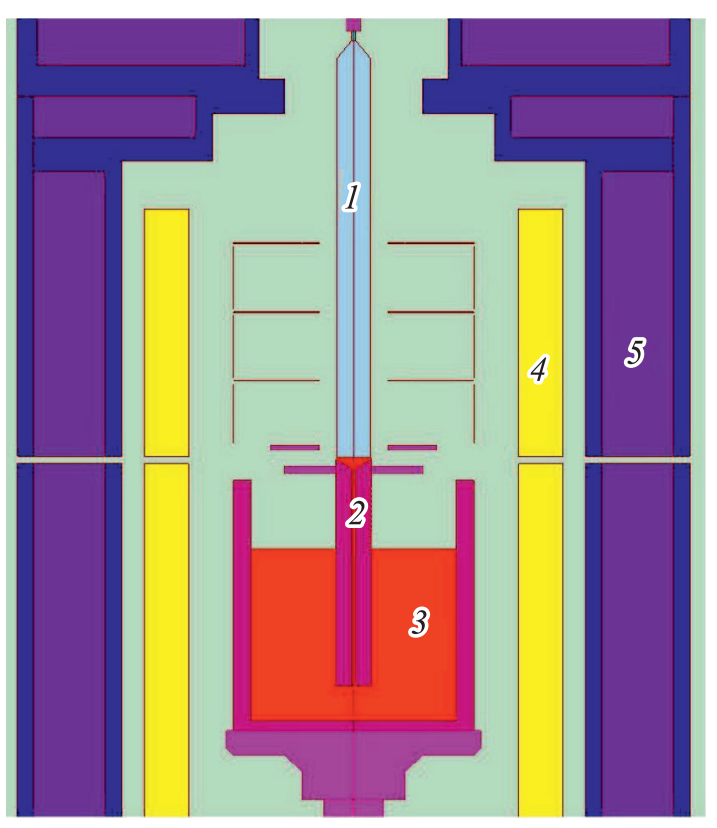

Рис. 3. Схема тепловой зоны выращивания профилированных кристаллов: 1 - кристалл сапфира, $2-$ формообразователь, 3 - расплав в тигле, 4 - нагреватель, 5 - экранировка. 


\section{3. Постановка задачи численного моделирования процессов теплообмена}

Схема расчетной модели приведена на рис. 3. Расчеты выполнены с помощью пакета программ Basic CGSim [20] для стержней сапфира диаметром $10 \mathrm{~mm}$, выращиваемых со скоростью 30, 60 и $120 \mathrm{~mm} / \mathrm{h}$, и двух конструкций формообразователя - с плоской верхней горизонтальной поверхностью и конической с углом раствора конуса $120^{\circ}$. Расстояние от верхней кромки формообразователя до тройной точки составляло $0.5 \mathrm{~mm}$. Температура кристаллизации бралась равной 2313 K. Уравнения переноса тепла излучением решались комбинацией метода дискретных ординат и метода трассировки лучей $[5,21]$, который и лежит в основе алгоритма пакета Basic CGSim. Оставшиеся значения свойств материалов и границ брались такими же, как и в работе [4]. Впервые указанная выше методика была успешно использована при моделировании процессов теплообмена при выращивании кристаллов BGO $\left(\mathrm{Bi}_{4} \mathrm{Ge}_{3} \mathrm{O}_{12}\right)$ в структуре эвлитина низкоградиентным методом Чохральского [22].

Конвекцией в расплаве пренебрегалось из-за малости ее вклада в процессы теплообмена в объеме мениска расплава по сравнению с радиационным и кондуктивным переносом тепла.

\section{4. Результаты модельных расчетов}

Были проведены расчеты температурных полей в кристалле и мениске расплава. Исследованы зависимости формы фронта кристаллизации, градиентов температуры в кристалле и расплаве, а также переохлаждения в мениске расплава от скорости роста и коэффициентов поглощения в кристалле и расплаве.

\section{1. Сравнение расчетов температурного поля для плоского и конического формообразователей}

Расчеты были выполнены при базовых значениях коэффициентов поглощения в расплаве $k_{\text {melt }}=1400 \mathrm{~m}^{-1}$ и кристалле $k_{\text {cryst }}=17 \mathrm{~m}^{-1}$. Видно, что при плоском формообразователе (рис. 4,a) фронт кристаллизации имеет волнообразный характер в отличие от практически линейного и прижатого к конусной поверхности формообразователя (рис. 4, $b$ ). В первом случае волнообразный вид фронта кристаллизации может приводить к скоплению выделяющегося на фронте растворенного газа и образованию крупных пузырей вблизи центральной части сечения.
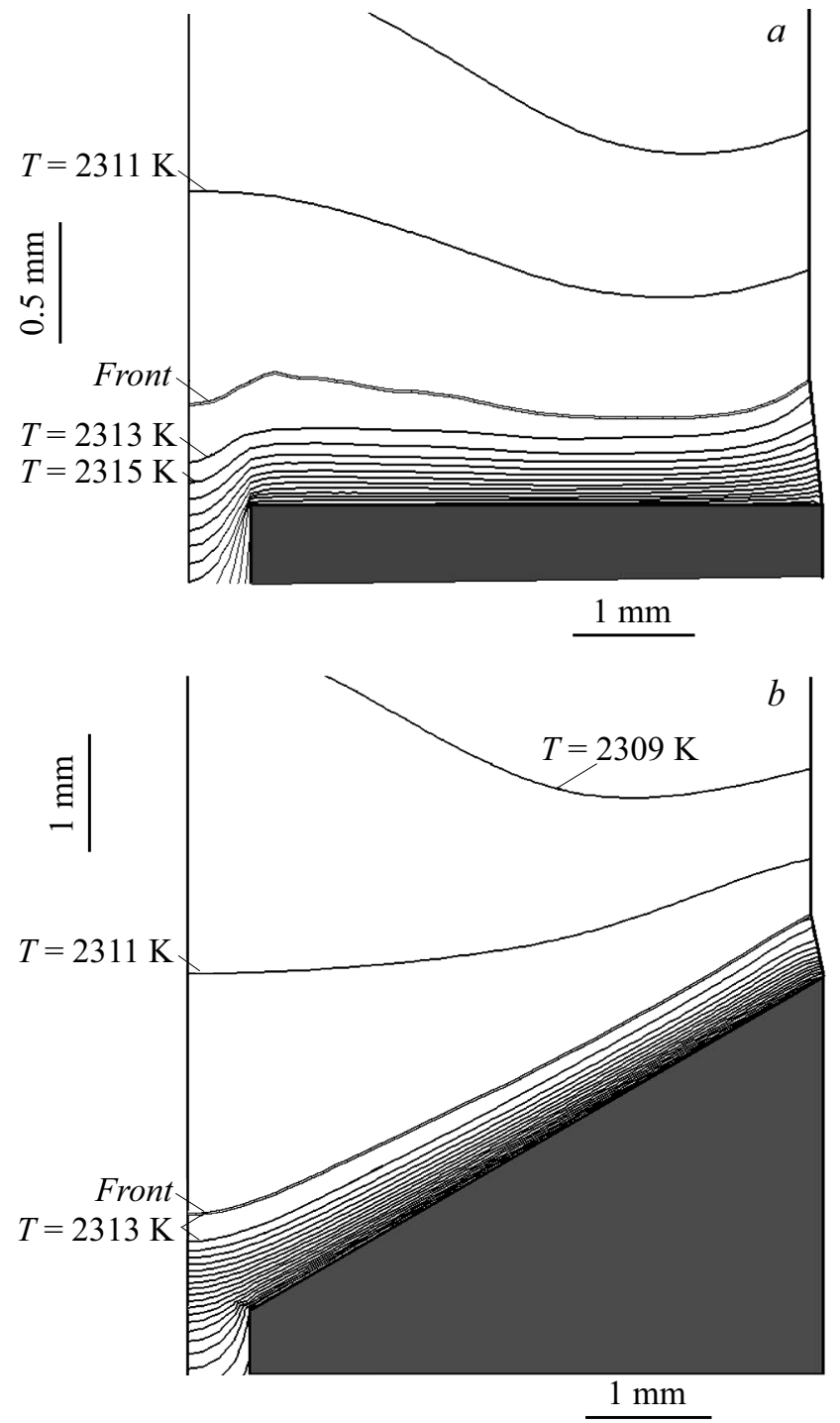

Рис. 4. Рассчитанное поле температуры в кристалле и мениске расплава для плоского $(a)$ и конического $(b)$ формообразователей. В варианте $(a)$ вертикальный масштаб увеличен в 2 раза.

\section{2. Зависимость распределения температуры от скорости выращивания для плоского и конического формообразователей}

На рис. 5 показаны кривые распределения температуры по оси вытягивания в мениске расплава и кристалле при разных скоростях выращивания для плоского (рис. 5, $a$ ) и конического (рис. $5, b)$ формообразователей. Видно, что с увеличением скорости градиент температуры в мениске расплава становится существенно большим, чем в кристалле, хотя одновременно оба градиента растут. Из графиков также видно, что под фронтом есть области переохлажденного расплава. Величина этой области переохлаждения вдоль оси роста зависит от скорости выращивания. С увеличением скорости от 30 до $120 \mathrm{~mm} / \mathrm{h}$ переохлаждение увеличивается практически линейно с 0.5 до $5.5 \mathrm{~K}$ и протяженность этой области 

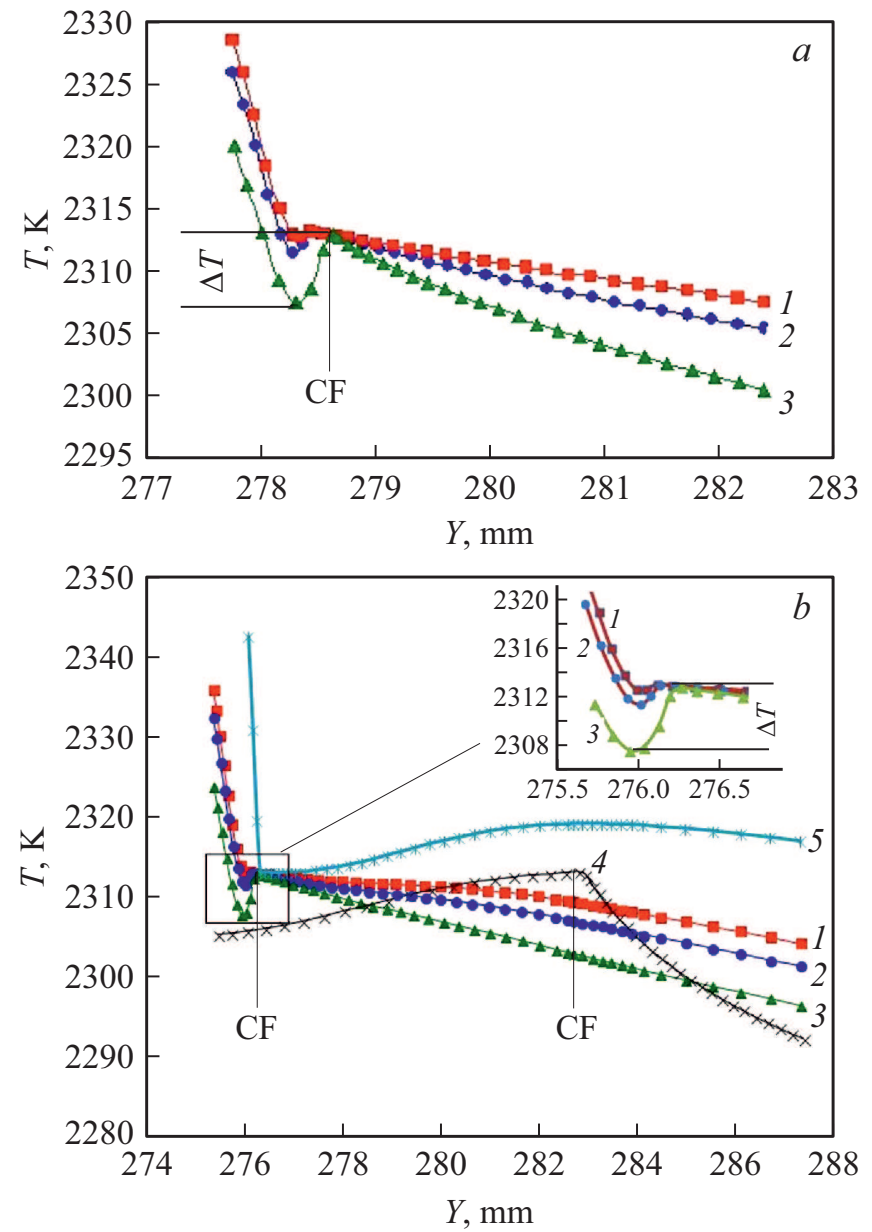

Рис. 5. Распределение температуры по оси выращивания кристалла для плоского $(a)$ и конического $(b)$ формообразователей при скоростях выращивания 30 (кривая 1), 60 (кривая 2) и $120 \mathrm{~mm} / \mathrm{h}$ (кривая 3). $\Delta T$ - переохлаждение в мениске расплава, CF - положение фронта кристаллизации. Для сравнения приведено распределение температуры для случая непрозрачных кристалла и расплава $((b)$, кривая 4$)$ и для случая непрозрачного расплава $((b)$, кривая 5$)$. В верхнем правом углу $(b)$ показано распределение температуры в области фронта кристаллизации в увеличенном масштабе.

по оси роста возрастает с 0.2 до $0.6 \mathrm{~mm}$ для обоих типов геометрии формообразователя.

Чтобы показать необходимость обязательного учета радиационного переноса тепла, были проведены расчеты для случая непрозрачного кристалла и расплава (рис. 5, $b$, кривая 4 ) и для случая непрозрачного расплава (рис. 5, $b$, кривая 5). Видно, что при непрозрачности как кристалла, так и расплава фронт кристаллизации изгибается резко вверх (кривая 5 на рис. $6, b$ ), градиент температуры в кристалле резко возрастает, а температура расплава уменьшается по глубине мениска, т.е. получается, что весь мениск расплава переохлажден и это приведет к его кристаллизации. Эти результаты коррелируют с расчетами, проведенными в [1] при тех же предположениях. Такой вариант расчета не реален на практике при выращивании полупрозрачных кристаллов. В случае непрозрачности только расплава можно видеть, что градиент температуры в мениске расплава резко возрастает, а в кристалле, наоборот, уменьшается, причем выше фронта кристаллизации появляется перегретая область на протяжении до $7 \mathrm{~mm}$. Такой случай также нереален на практике.

\section{3. Влияние коэффициентов поглощения в кристалле и характера отражения на форму фронта кристаллизации и температурное распределение}

На рис. 6 прослеживается изменение формы фронта кристаллизации при разных значениях коэффициента поглощения в кристалле. Видно, что для обоих типов формообразователей при уменьшении коэффициента поглощения (увеличении прозрачности кристалла) фронт кристаллизации опускается вниз и ближе прилегает к формообразователю. Расчеты также показывают, что при уменьшении коэффициента поглощения в кристалле с 40 до $5 \mathrm{~m}^{-1}$ уменьшается градиент температуры в кри-
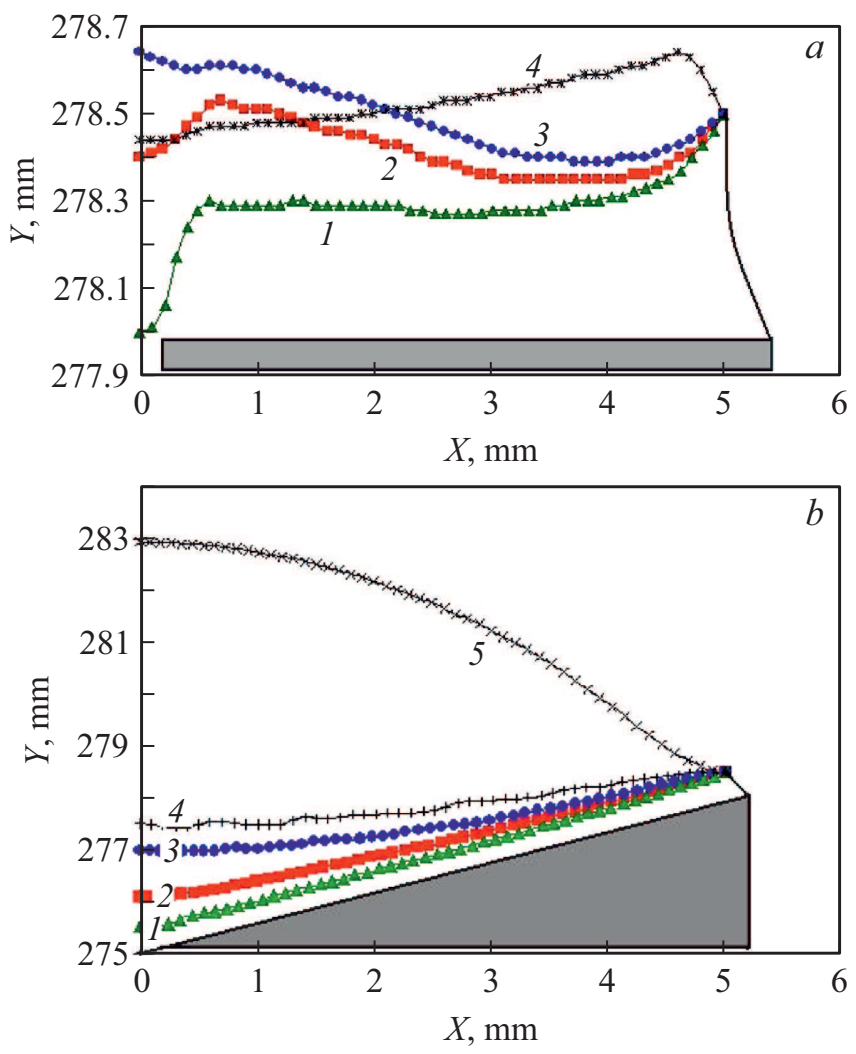

Рис. 6. Форма фронта кристаллизации для плоского $(a)$ и конического $(b)$ формообразователей при различных коэффициентах поглощения в кристалле сапфира: 5 (кривые 1), 17 (кривые 2), 40 (кривые 3). Кривые 4 на (a) и (b) форма фронта кристаллизации в предположении диффузного характера отражения светового потока (для сравнения). Кривая 5 на $(b)$ - форма фронта кристаллизации для случая непрозрачных кристалла и расплава. 
сталле и возрастает примерно на $3.5 \mathrm{~kW}$ тепловыделение на нагревателе. Это подтверждается в экспериментах по выращиванию кристаллов сапфира, а именно, выращивание более прозрачных кристаллов требует большего прибавления мощности на нагревателе в начальной стадии процесса [23].

На этом же рисунке для сравнения приведены формы фронта кристаллизации при диффузном характере отражения световодного потока от стенок кристалла (кривая 4). Видно, что для плоского формообразователя вид фронта кристаллизации резко изменяется, появляется кольцеобразный вогнутый вверх участок вблизи боковой поверхности кристалла. Для конического формообразователя влияние диффузного отражения приводит также к подъему фронта вверх и появлению волнообразности (кривая 4 , рис. $6, b$ ).

Изменение коэффициента поглощения в кристалле влияет также на распределение температуры в кристалле и в мениске расплава: увеличение коэффициента увеличивает градиент температуры в кристалле и снижает градиент в мениске. Этот эффект наблюдается для обоих типов формообразователей.

\section{5. Обсуждение результатов}

Представляет интерес сопоставление результатов модельных расчетов с экспериментальными наблюдениями. Прежде всего, заметим, что во всех расчетах в мениске расплава есть переохлаждение в диапазоне от 0.5 до 5.5 К. К сожалению, измерить переохлаждение в реальном процессе не представляется возможным, но захват переохлажденных областей наблюдается в реальном процессе при некоторых режимах роста. Сопоставление расчетов для плоского и конического формообразователей при номинальных (базовых) режимах показывает, что фронт кристаллизации значительно опускается при наклоне его кромок внутрь, и тем самым уменьшается вероятность захвата фронтом переохлажденной области, что согласуется с экспериментальными наблюдениями. При кристаллизации с плоского формообразователя на участках с вогнутым фронтом кристаллизации может образовываться ячеистая структура, которая может способствовать захвату пузырьков газа растущим кристаллом или захвату переохлажденного объема жидкости, который кристаллизуется выше фронта.

В работе [1] рассчитано температурное поле для случая выращивания стержня сапфира диаметром $12 \mathrm{~mm}$, но переохлажденных областей выявлено не было. К сожалению, форма представления результатов расчета температуры в виде цветовых полей не позволяет сопоставить эти расчеты с нашими результатами. Отметим только, что авторы приводят данные по вертикальному перепаду температур вдоль свободной поверхности мениска. Он составляет 12 и $250 \mathrm{~K}$ для случая непрозрачного и полупрозрачного (с учетом радиационного переноса тепла) кристалла соответственно. Наши расчеты показывают другие данные: -9.6 и $27 \mathrm{~K}$. Нам представляется, что перепад температуры по мениску в $250 \mathrm{~K}$ - это явно завышенное значение, и наши данные ближе к реальности. В работе [24] на основе другой модели также была рассчитана зависимость перепада температур по высоте мениска от скорости выращивания. Показано, что этот перепад уменьшается до нуля при скорости $3.6 \mathrm{~mm} / \mathrm{min}$, что является верхним пределом скорости. При скорости роста $1 \mathrm{~mm} / \mathrm{min}$ перепад по мениску составляет $10-15 \mathrm{~K}$, что подтверждается экспериментальными данными и близко к полученным нами результатам.

Прямых экспериментальных данных по измерению температурного распределения в стержнях сапфира диаметром $10 \mathrm{~mm}$ нет. В литературе есть данные по измерению температуры с помощью вращиваемых термопар в лентах сапфира $24 \times 2.5 \mathrm{~mm}$ [25] и трубках диаметром $8 \mathrm{~mm}$ [26], а также пирометрических измерениях в сапфировых трубках диаметром $18 \mathrm{~mm}$ [27]. В этих работах перепад температур на расстоянии $5 \mathrm{~mm}$ от фронта кристаллизации составляет приблизительно $40-60 \mathrm{~K}$. В наших расчетах этот перепад составил $8-15 \mathrm{~K}$. Такое различие, возможно, связано с тем, что по сравнению с цилиндрическим профилем, рассмотренным в наших расчетах, в плоских и тонкостенных кристаллах теплоотдача идет значительно интенсивней.

Отметим также, что в отличие от выращивания непрозрачных кристаллов градиент температуры в расплаве больше, чем в кристалле. Этот результат может быть связан с учетом радиационного переноса тепла не только в кристалле, но и в мениске расплава.

\section{Выводы}

Таким образом, в работе показано, что объемный радиационный перенос тепла в кристалле и мениске расплава играет важную роль в формировании теплового поля и фронта кристаллизации. Он приводит к появлению переохлажденных областей под фронтом кристаллизации и для случая плоского формообразователя вогнутых участков фронта кристаллизации, что может влиять на устойчивость процесса.

Проделанные модельные расчеты показали хорошее согласие с наблюдаемыми экспериментальными данными. Показано, что, с точки зрения устойчивости процесса кристаллизации, более предпочтителен вариант с коническим формообразователем. Он позволяет получить устойчивый фронт кристаллизации вдоль конусных кромок формообразователя.

\section{Благодарности}

Авторы выражают благодарность В.С. Юфереву за интерес к настоящей работе и полезные обсуждения ее результатов. 


\section{Конфликт интересов}

Авторы заявляют, что у них нет конфликта интересов.

\section{Список литературы}

[1] Stelian C., Barthalay N., Duffar T. // J. Cryst. Growth. 2017. Vol. 470. P. 159-167.

[2] Оцисик М.Н. Сложный теплообмен. М.: Мир, 1976. С. 367.

[3] Stelian C., Sen G., Barthalay N., Duffar T. // J. Cryst. Growth. 2016. Vol. 453. P. 90-98.

[4] Demina S.E., Kalaev V.V. // J. Cryst. Growth. 2011. Vol. 320. P. 23-27.

[5] Rukolaine S.A., Vasilyev M.G., Yuferev V.S., Mamedov V.M. // J. Quant. Spectr. Radiat. Transfer. 2004. Vol. 84. N 4. P. $371-382$.

[6] Hur M.J., Han X.F., Choi H.G., Yi K.W. // J. Cryst. Growth. 2017. Vol. 474. P. 24-30.

[7] Hur M.J., Han X.F., Song D.S., Kim T.H., Lee N.J., Jeong Y.J., Yi K.W. // J. Cryst. Growth. 2014. Vol. 385. P. 22-27.

[8] Wu M., Liu L., Ma W. // J. Cryst. Growth. 2017. Vol. 474. P. $31-36$.

[9] Васильев М.Г., Юферев В.С. // ЖТФ. 1982. Т. 52. Вып. 7. C. 1280-1284. [Vasil'ev V.G., Yuferev V.S. // Tech. Phys. 1982. Vol. 27. N 7. P. 779-781.]

[10] Юферев В.С., Колесникова Э.Н. // ЖТФ. 1982. Т. 52. Вып. 7. C. 1285-1290. [Yuferev V.S., Kolesnikova E.N. // Tech. Phys. 1982. Vol. 27. N 7. P. 782-784.]

[11] Bufetova G.F., Rusanov S.Ya., Seregin V.F., Pyrkov Yu.N., Tsvetkov V.B. // J. Cryst. Growth. 2017. Vol. 480. P. 85-89.

[12] Лингарт Ю.К., Петров В.А., Тихонова Н.А. // ТВТ. 1982. T. 20. Вып. 5. С. 872-880. [Lingart Y.K., Petrov V.A., Tikhonova N.A. // High Temp. 1982. Vol. 20. N 5. P. 706-713.]

[13] Лингарт Ю.К., Петров В.А., Тихонова Н.А. // ТВТ. 1982. T. 20. Вып. 6. С. 1085-1092. [Lingart Y.K., Petrov V.A., Tikhonova N.A. // High Temp. 1982. Vol. 20. N 6. P. 856-862.]

[14] Антонов П.И., Бахолдин С.И., Васильев М.Г., Тропn Э.А., Юферев В.С. // Изв. РАН. Сер. физ. 1980. Т. 44. Вып. 2. C. 269-275. [Antonov P.I., Bakholdin S.I., Vasiliev M.G., Tropp E.A., Yuferev V.S. // Bull. Russ. Acad. Sci. Phys. 1980. Vol. 44. N 2. P. $36-41$.]

[15] Бакалейников Л.А., Васильев М.Г. // ЖТФ. 1988. Т. 58. Вып. 12. C. 2279-2285. [Bakaleinikov L.A., Vasil'ev V.G. // Tech. Phys. 1988. Vol. 33. N 12. P. 1391-1394.]

[16] Крымов В.М., Денисов А.В., Саллум М.И., Бахолдин С.И., Мамедов В.М., Юферев В.С., Русанов А.А., Смирнов П.В. // Изв. РАН. Сер. физ. 2009. Т. 73. Вып. 10. C. 1436-1440. [Krymov V.M., Denisov A.V., Sallum M.I., Bakholdin S.I., Mamedov V.M., Yuferev V.S., Rusanov A.A., Smirnov P.V. // Bull. Russ. Acad. Sci. Phys. 2009. Vol. 73. N 10. P. 1355-1359.]

[17] Bityukov V.K., Petrov V.A. // Appl. Phys. Res. 2013. Vol. 5. N 1. P. $51-71$.

[18] Dobrovinskaya E.R., Litvinov L.A., Pischik V. Sapphire: Material, Manufacturing, Applications. Berlin: Springer, 2009. $481 \mathrm{p}$.

[19] Minissale M., Zeweldi G.B., Bisson R., Gallais L. // Nucl. Fusion. 2018. Vol. 58. P. 1-8.
[20] CGSim Theory Manual Vol. 20. STR Group, Inc., St. Petersburg, Russia, 2019.

[21] Rukolaine S.A., Vasilyev M.G., Yuferev V.S., Mamedov V.M. Proceed. Eurotherm 73 on Computational Thermal Radiation in Participating Media, 15-17 April 2003, Mons, Belgium. Vol. 2. P. $1-10$.

[22] Vasilyev M.G., Budenkova O.N., Yuferev V.S., Kalaev V.V., Shlegel V.N., Ivannikova N.V., Vasiliev Ya.V., Mamedov V.M. // J. Cryst. Growth. 2005. Vol. 275. P. e745-e750.

[23] Антонов П.И., Бахолдин С.И., Крымов В.М., Куандыков Л.Л., Москалев А.В. // Изв. РАН. Сер. физ. 2004. T. 68. Вып. 6. С. 828-833. [Antonov P.I., Bakholdin S.I., Krymov V.M., Kuandykov L.L., Moskalev A.V. // Bull. Russ. Acad. Sci. Phys. 2004. Vol. 68. N 6. P. 938-941.]

[24] Carroz L., Duffar T. // J. Cryst. Growth. 2018. Vol. 489. P. 5-10.

[25] Krymov V.M., Kurlov V.N., Antonov P.I., Theodore F., Delepine J. // J. Cryst. Growth. 1999. Vol. 198/199. P. 210-214.

[26] Антонов П.И., Бахолдин С.И., Васильев М.Г., Крымов В.М., Москалев А.В., Юферев В.С. // Изв. РАН. Cер. физ. 1994. Т. 58. Вып. 9. С. 72-80. [Antonov P.I., Bakholdin S.I., Vasiliev M.G., Krymov V.M., Moskalev A.V., Yuferev V.S. // Bull. Russ. Acad. Sci. Phys. 1994. Vol. 58. N 9. P. $1475-1481$.]

[27] Алишоев А.Л., Затуловский Л.М., Лингарт Ю.К., Шур Д.Л. // Изв. РАН. Сер.физ. 1988. Т. 52. Вып. 10. C. 1985-1987. [Alishoev A.L., Zatulovskii L.M., Lingart Yu.K., Shur D.L. // Bull. Russ. Acad. Sci. Phys. 1988. Vol. 52. N 10. P. 99-100.] 